\title{
Posterior Scleritis in Familial Mediterranean Fever
}

\author{
Ahmad M. Mansour ${ }^{a}$ b Lama Khatib ${ }^{c}$ Hana A. Mansour ${ }^{a}$ \\ aDepartment of Ophthalmology, American University of Beirut, Beirut, Lebanon; \\ ${ }^{b}$ Department of Ophthalmology, Rafic Hariri University Hospital, Beirut, Lebanon; \\ 'Department of Ophthalmology, Clemenceau Medical Center, Beirut, Lebanon
}

\section{Keywords}

Familial Mediterranean fever · Posterior scleritis

\begin{abstract}
Purpose: Familial Mediterranean fever (FMF) is a monogenic autoinflammatory disease presenting as sporadic paroxysmal attacks of fever and abdominal pain. The inflammation of serosal spaces, joints, and skin is caused by the production of an abnormal protein called pyrin. Ocular pathology is scarce in FMF. Case Report: Herein we describe a case of FMF presenting with painful loss of vision in the left eye. Serous macular detachment assessed by OCT, leaky pinpoint subretinal foci temporal to the fovea examined by fluorescein angiography, scleral and choroidal thickening seen on ultrasonography, and a negative systemic workup for vasculitis established the diagnosis of FMF-related posterior scleritis. The posterior scleritis responded promptly to moderate-dose oral corticosteroids with return of vision to baseline and resolution of the subretinal fluid. Conclusions: FMF rarely involves the posterior pole. Visual loss in FMF results from either posterior scleritis or posterior uveitis. A high degree of suspicion of posterior scleritis is warranted in female patients with known FMF presenting with cloudy serous macular detachment.

(C) 2019 The Author(s)

Published by S. Karger AG, Basel
\end{abstract}




\section{Introduction}

Familial Mediterranean fever (FMF) is the earliest known autoinflammatory disorder manifesting as periodic self-limited unprovoked attacks of fever, arthritis, peritonitis, and erysipelas-like erythema [1]. FMF is often associated with autoimmune diseases like rheumatoid arthritis or Behçet disease [1]. It involves predominantly populations of Jewish, Arab, Armenian, and Turkish descent originating from around the Mediterranean Sea [2-12]. In 1972 a new era in the treatment of FMF began with the introduction of colchicine, which decreases the frequency of attacks, markedly improves quality of life, and delays the onset of renal failure and development of amyloidosis [1]. Inheritance is autosomal recessive, caused by a mutation in the Mediterranean fever (MEFV) gene on chromosome 16 [1]. The pyrin protein encoded by the $M E F V$ gene plays an important role in the regulation of inflammation. FMF rarely involves the posterior pole of the eye $[11,12]$. In this report, we present a case of FMF with retinal findings.

\section{Case Report}

A 16-year-old girl had FMF confirmed by genetic testing (mutation in the $M E F V$ gene). Attacks included recurrent bouts of high fever and abdominal pain lasting for 3 days twice yearly since the age of 3 years. Her symptoms were well controlled with oral colchicine (1.5 $\mathrm{mg}$ ) since the age of 7 years. Recently she started manifesting ankle pain and edema along with the attacks. On continued colchicine therapy, the attacks became mild and lasted half a day. Following high levels of perceived stress, she presented to us with a 1-week history of painful blurry vision in the left eye. Best corrected visual acuity was 20/100 (6/30) in the left eye with mild ciliary injection, and serous macular detachment with cloudy serous fluid on fundus examination. The anterior segments and vitreous were normal in both eyes. SD-OCT documented a serous macular detachment (Fig. 1). Intravenous fluorescein angiography revealed a round sector of multiple deep pinpoint subretinal dye leakages temporal to the fovea. A B-scan documented posterior focal thickening of the choroid and sclera temporal to the macula (Fig. 1).

The systemic workup was negative for rheumatic markers (ESR, CRP, ANA, c-ANCA, and p-ANCA) or infectious etiologies (PPD skin test, toxoplasma IgG and IgM). The patient denied having oral ulcers or sexual activity. She was started on $20 \mathrm{mg}$ prednisone orally. Two weeks later, visual acuity had improved to 20/25 (6/7.5) with near resolution of the dye leakage and subretinal fluid on fluorescein angiography (Fig. 2). The oral steroid therapy was tapered to $10 \mathrm{mg}$ for 5 days, $5 \mathrm{mg}$ for 14 days, and $2.5 \mathrm{mg}$ for 14 days. Six weeks after initiation of therapy, there was complete restoration of the posterior pole anatomy back to normal (Fig. 3).

\section{Discussion}

Retinal involvement in FMF is rare [1-12]. Baghdassarian et al. [12] did not find any specific retinal findings in 50 Lebanese patients with FMF. Posterior pole findings have included few cases of anterior uveitis [3], posterior uveitis [3, 6, 10,11], intermediate uveitis [3], frosted branch angiitis [7, 8], acute posterior multifocal placoid pigment epitheliopathy [9], and episcleritis [2, 5] or scleritis [3, 4]. Posterior scleritis was related to FMF in the present case, with no evidence of any other associated systemic autoinflammatory disease. 
In 1982, Yazici and Pazarli [13] described episcleritis in a 26-year-old Armenian female on colchicine therapy for FMF. In 1985, nodular episcleritis with preserved vision was reported in 2 subjects by Scharf et al. [2], the first patient being a 34-year-old Moroccan and the second a 36-year-old Iranian; both responded to topical corticosteroids. Akman et al. [6] also described episcleritis in a 7-year-old Turkish boy, which occurred while he was on colchicine prophylaxis and was controlled using topical steroids and oral nonsteroidal anti-inflammatory drugs. Finally, Berestizschevsky et al. [5] described a 40-year-old Arabic woman with nodular episcleritis. Despite treatment with topical and systemic corticosteroids, she required surgical correction of resulting symblepharon [5]. There is 1 case of posterior scleritis in a 14year-old Turkish male treated initially with intravenous methylprednisolone followed by oral prednisolone [3]. His visual acuity improved from 20/200 (6/60) to 20/20 (6/6) [3].

The pathogenesis of retinal findings in FMF appears to be related to the protein pyrin. Pyrin is encoded by the $M E F V$ gene and plays a key role in inflammatory signaling pathways. $M E F V$ gene mutations result in reduction of pyrin production, resulting in a prolonged inflammatory response mounted specifically by neutrophils and macrophages. Experimental data point to the role of pyrin in both macrophage-mediated interleukin- $1 \beta$ production and chemotactic or phagocytotic processes of neutrophils [1].

Although episcleritis is the most common manifestation of ocular inflammation in FMF, clinicians should remember that the disease may also present with scleritis and uveitis. Posterior scleritis is often misdiagnosed due to its clinical polymorphism. It must be considered in the differential diagnosis of exudative retinal detachment [14]. Because it is rare, a high index of suspicion is necessary. Posterior scleritis affects women more often than men, and exudative macular detachment in posterior scleritis is more common in women [14]. An associated systemic inflammatory or autoimmune pathology occurs in up to $40 \%$ of patients and should be ruled out first [1], such as rheumatoid arthritis, systemic lupus erythematosus, granulomatosis with polyangiitis, sarcoidosis, Crohn's disease, Behçet disease, periarteritis nodosa, relapsing polychondritis, IgA nephropathy, and FMF. Infectious etiologies to be considered include syphilis, herpes zoster, and tuberculosis. When a negative workup result is obtained, a prompt diagnosis of FMF-related scleritis is warranted in order to initiate appropriate treatment. Orbital CT (scleral thickening) [15] and ultrasonography (sclerochoroidal thickening), OCT (subretinal fluid and choroidal thickening) [14], and fluorescein angiography (deep subretinal foci of dye leakage) [14] are valuable tools for establishing the diagnosis of posterior scleritis.

FMF is a common autoinflammatory systemic disease around the Mediterranean basin; however, FMF-associated ocular pathology remains rare. Ophthalmologists need to question/investigate patients for FMF in cases of an established diagnosis of scleritis or uveitis. Vice versa, posterior scleritis needs to be included in the differential diagnosis of exudative maculopathy or acute visual loss in patients with FMF.

\section{Statement of Ethics}

The authors have no ethical conflicts to disclose.

\section{Disclosure Statement}

The authors have no conflicts of interest to disclose. 


\section{References}

1 Petrushkin H, Stanford M, Fortune F, Jawad AS. Clinical Review: Familial Mediterranean fever - an overview of pathogenesis, symptoms, ocular manifestations, and treatment. Ocul Immunol Inflamm. 2016 Aug;24(4):422-30.

2 Scharf J, Meyer E, Zonis S. Episcleritis associated with familial Mediterranean fever. Am J Ophthalmol. 1985 Aug;100(2):337-9.

3 Yazici A, Ozdal P, Yuksekkaya P, Elgin U, Teke MY, Sari E. Ophthalmic manifestations in familial Mediterranean fever: a case series of 6 patients. Eur J Ophthalmol. 2014 Jul-Aug;24(4):593-8.

4 Akalin T, Demirag MD, Tezcan ME, Ozturk MA. Scleritis and sudden hearing loss associated with familial Mediterranean fever. Clin Exp Rheumatol. 2010 Jul-Aug;28(4 Suppl 60):S103-4.

5 Berestizschevsky S, Weinberger D, Avisar I, Avisar R. Episcleritis associated with familial Mediterranean fever. Isr Med Assoc J. 2008 Apr;10(4):318-9.

6 Akman A, Varan B, Akova YA, Aydin P. Ocular involvement in siblings with familial mediterranean fever. J Pediatr Ophthalmol Strabismus. 2001 Mar-Apr;38(2):114-6.

7 Satoh S, Itoh C, Nakamura N. [A case of frosted branch angiitis associated with retinal vein occlusion as a complication of familial Mediterranean fever]. Nippon Ganka Gakkai Zasshi. 2010 Jul;114(7):621-8.

8 Köse Ö, Willermain F, Caspers L, Postelmans L, El Ouardighi H, Guillaume MP, et al. Acute frosted retinal periphlebitis in a patient with Mediterranean fever. Retin Cases Brief Rep. 2018. [Epub ahead of print]

9 Georgakopoulos CD, Antonopoulos I, Makri OE, Vasilakis P, Liossis SN, Andonopoulos AP. Acute posterior multifocal placoid pigment epitheliopathy in a patient with familial Mediterranean fever. Clin Exp Optom. 2016 Jul;99(4):385-7.

10 Hirsh A, Huna R, Ashkenazi I, Bartov E, Blumenthal M. Recurrent bilateral panuveitis and rhegmatogenous retinal detachment in a patient with familial Mediterranean fever. Am J Ophthalmol. 1990 Dec;110(6):702-3.

11 Ozaltin F, Bakkaloglu A, Orhon M, Duzova A, Irkec M. Bilateral uveitis in a 7-year-old patient with familial Mediterranean fever. An extremely rare complication. Clin Exp Rheumatol. 2001 Sep-Oct;19(5 Suppl 24):S80-1.

12 Baghdassarian SA, Armenian HK, Khachadurian AK. Absence of ophthalmoscopic changes in familial paroxysmal polyserositis. Arch Ophthalmol. 1972 Dec;88(6):607-8.

13 Yazici H, Pazarli H. Eye involvement in a patient with familial Mediterranean fever. J Rheumatol. 1982 Jul-Aug;9(4):644.

14 Benson WE. Posterior scleritis. Surv Ophthalmol. 1988 Mar-Apr;32(5):297-316.

15 Osman Saatci A, Saatci I, Kocak N, Durak I. Magnetic resonance imaging characteristics of posterior scleritis mimicking choroidal mass. Eur J Radiol. 2001 Aug;39(2):88-91. 


\section{Case Reports in Ophthalmology}
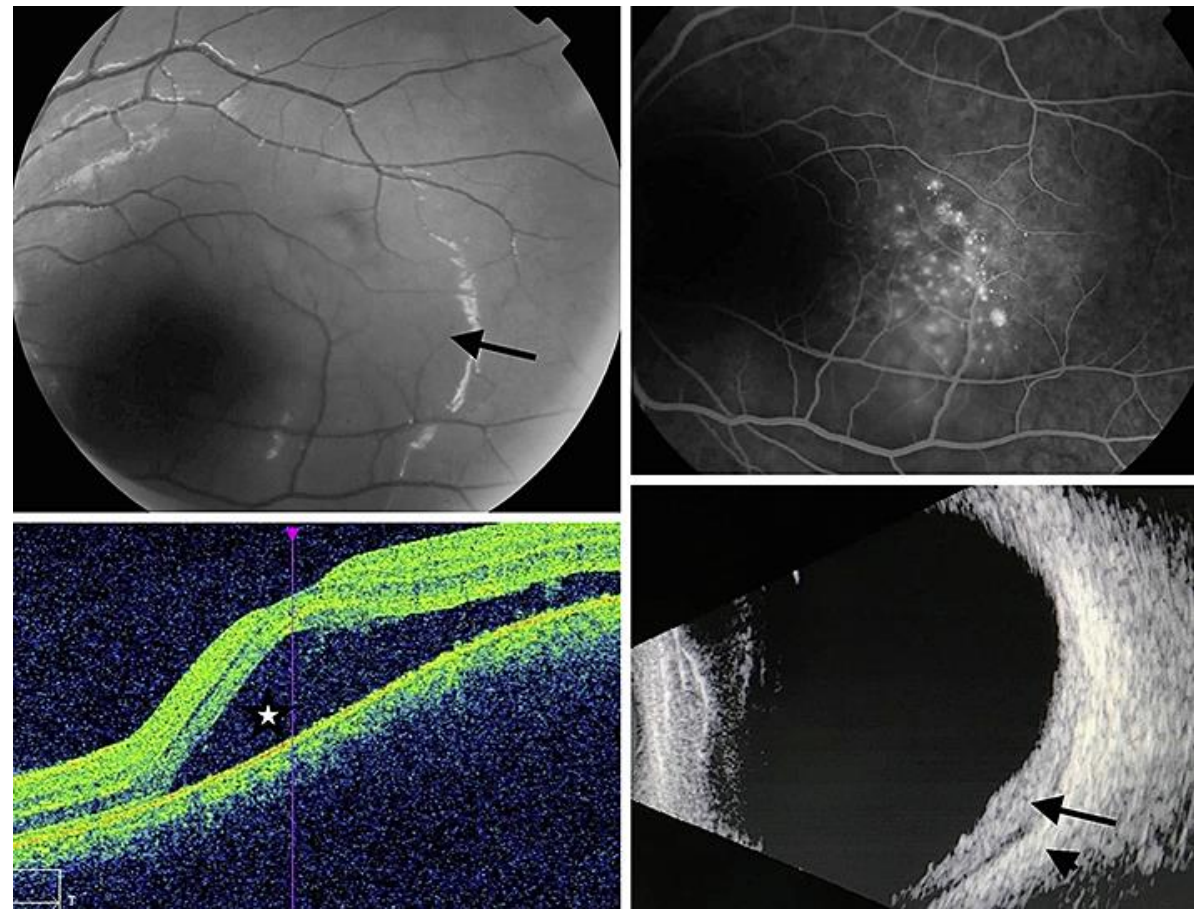

Fig. 1. At presentation. Posterior pole of the left eye showing a cloudy elevation of the macula (arrow, top left), pinpoint subretinal dye leakage on fluorescein angiography temporal to the fovea (top right), subretinal fluid on SD-OCT imaging (star, bottom left), and choroidal (arrow) and scleral (arrowhead) thickening on B-scan ultrasonography of the temporal macular region (bottom right). 


\section{Case Reports in Ophthalmology}

\begin{tabular}{l|l}
\hline Case Rep Ophthalmol 2019;10:134-139 \\
\hline DOI: 10.1159/000499600 & $\begin{array}{l}\text { @ 2019 The Author(s). Published by S. Karger AG, Basel } \\
\text { www.karger.com/cop }\end{array}$ \\
\hline
\end{tabular}
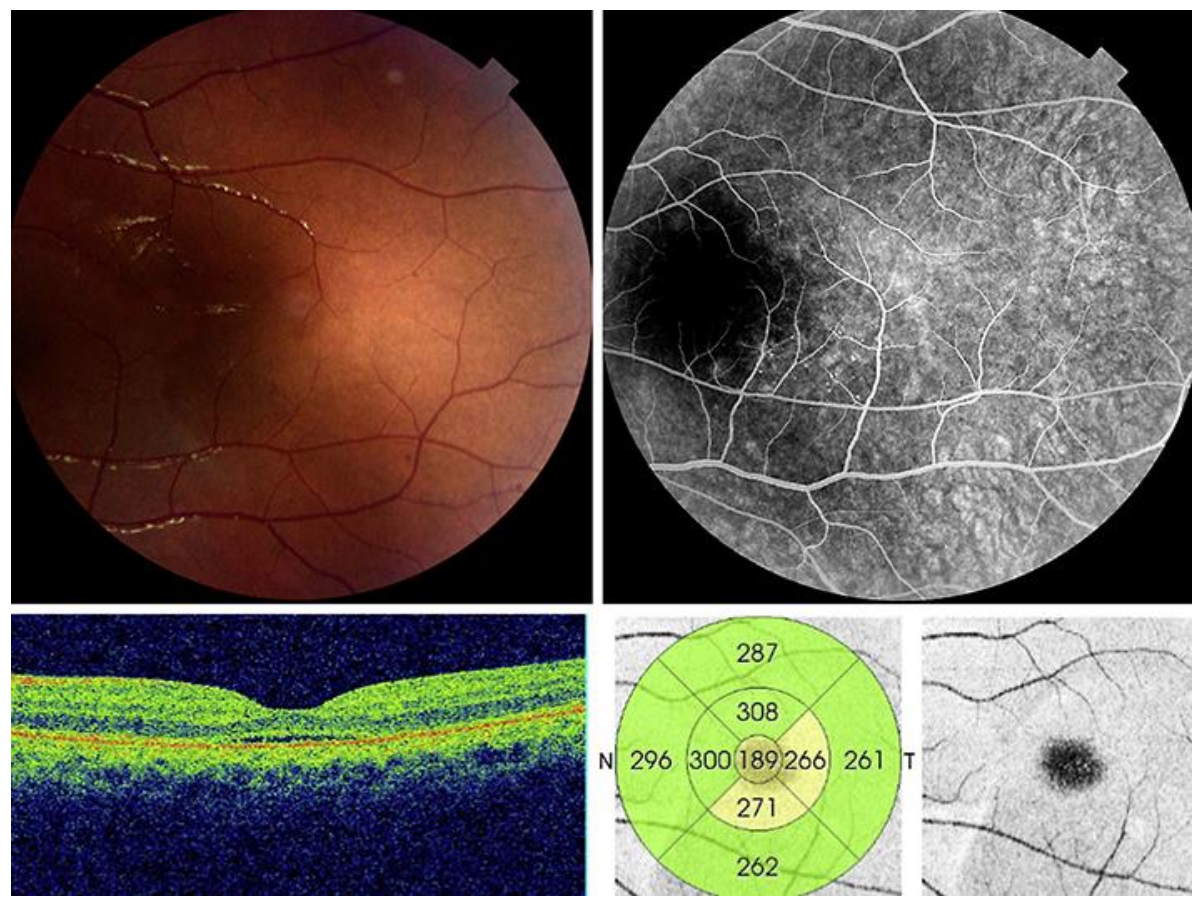

Fig. 2. Two weeks after oral corticosteroid intake. Minimal subretinal fluid on funduscopy (top left), fluorescein angiography (top right), and SD-OCT linear scans (bottom).
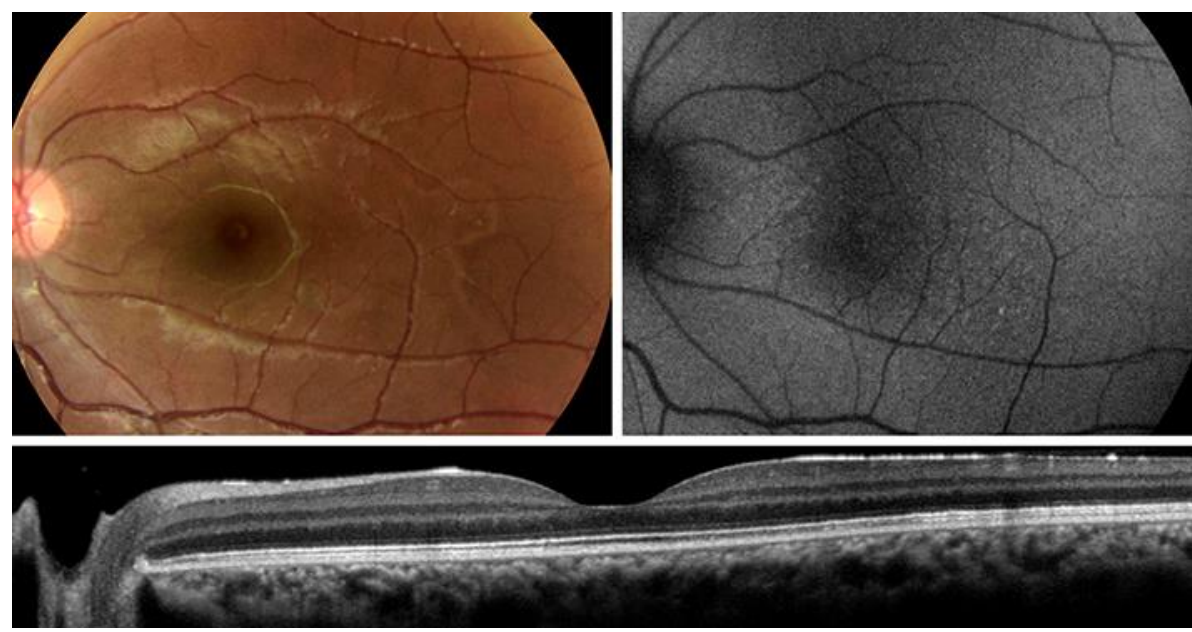

Fig. 3. Six weeks after the tapered regimen of oral corticosteroids. Normalization of the fundus on a photograph (top right) and a fundus autofluorescence image (top left). Complete resolution of the subretinal fluid and choroidal thickening (9-mm OCT scan, bottom). 